\title{
Longitudinal flow evolution and turbulence structure of dynamically similar, sustained, saline density and turbidity currents
}

\author{
T. E. Gray, ${ }^{1}$ Jan Alexander, ${ }^{1}$ and Mike R. Leeder ${ }^{1}$ \\ Received 3 June 2005; revised 17 January 2006; accepted 15 March 2006; published 10 August 2006.
}

[1] Experimental results are presented concerning flow evolution and turbulence structure of sustained saline and turbidity flows generated on $0^{\circ}, 3^{\circ}, 6^{\circ}$, and $9^{\circ}$ sloping ramps that terminate abruptly onto a horizontal floor. Two-component velocity and current density were measured with an ultrasonic Doppler velocity profiler and siphon sampler on the slope, just beyond the slope break and downstream on the horizontal floor. Three main factors influence longitudinal flow evolution and turbulence structure: sediment transport and sedimentation, slope angle, and the presence of a slope break. These controls interact differently depending on flow type. Sediment transport is accompanied by an inertial fluid reaction that enhances Reynolds stresses in turbidity flows. Thus turbidity flows mix more vigorously than equivalent saline density flows. For saline flows, turbulent kinetic energy is dependent on slope, and rapid deceleration occurs on the horizontal floor. For turbidity flows, normalized turbulent kinetic energy increases downstream, and mean streamwise deceleration is reduced compared with saline flows. The slope break causes mean bed-normal velocity of turbidity flows to become negative and have a gentler gradient compared with other locations. A reduction of peak Reynolds normal stress in the bed-normal direction is accompanied by an increase in turbulent accelerations across the rest of the flow thickness. Thus the presence of particles acts to increase Reynolds normal stresses independently of gradients of mean velocity, and sediment transport increases across the break in slope. The experiments illustrate that saline density currents may not be good dynamic analogues for natural turbidity currents.

Citation: Gray, T. E., J. Alexander, and M. R. Leeder (2006), Longitudinal flow evolution and turbulence structure of dynamically similar, sustained, saline density and turbidity currents, J. Geophys. Res., 111, C08015, doi:10.1029/2005JC003089.

\section{Introduction}

[2] Turbidity currents are particulate gravity currents that transport sediment in oceans, seas and lakes [e.g., Daly, 1938; Johnson, 1938; Kuenen and Migliorini, 1950; Normark et al., 1993; Kneller and Buckee, 2000; Peakall et al., 2001]. Sustained turbidity currents (STCs) arise from prolonged underflows at river mouths or from retrogressive mass movements [Mulder et al., 1998a, 1998b; Kineke et al., 2000; Parsons et al., 2001; Mulder et al., 2003]. A wide range of turbidites with fine-grained and coarse-grained end-members has been identified in the geological record [Normark et al., 1993]. In fine-grained STCs mean downstream velocity decays slowly with distance as the sediment settling velocity is (vanishingly) small and the driving buoyancy force is maintained [Gladstone et al., 1998]. These flows have been likened to nonparticulate currents where the density contrast between the two fluids arises from either salinity contrasts or temperature differences, and

\footnotetext{
${ }^{1}$ School of Environmental Sciences, University of East Anglia, Norwich, UK.

Copyright 2006 by the American Geophysical Union. 0148-0227/06/2005JC003089\$09.00
}

indeed both these properties can influence flow behavior. However, fluid-sediment interactions influence the turbulence structure of fine and coarse-grained particulate flows and sediment exchange with the bed alters the driving buoyancy force [Parker et al., 1986; Pratson et al., 2000; McCaffrey et al., 2003; Baas et al., 2005]. Flows transporting a mixed-size load also exhibit nonlinear behavior; a small amount of fines added to a coarse-particle flow greatly increases the transport distance of the coarser sediment, whereas coarse sediment added to a predominately finegrained flow has little affect on velocity decay [Gladstone et al., 1998; Salaheldin et al., 2000].

[3] Saline density currents form simple analogues to natural turbidity flows, and have proved invaluable in understanding large-scale flow mechanics [e.g., Keulegan, 1957; Simpson and Britter, 1979; Middleton, 1993; Kneller and Buckee, 2000]. Experimental turbidity currents have the advantage that deposits may be examined and trends relating flow structure to deposit variety may be determined [Middleton, 1993]. However, comparisons of saline and turbidity currents are scarce. Middleton [1966] used plastic beads as a surrogate for suspended sediment to compare flow morphology and front propagation speed with saline density currents. García [1993] compared hydraulic jumps 


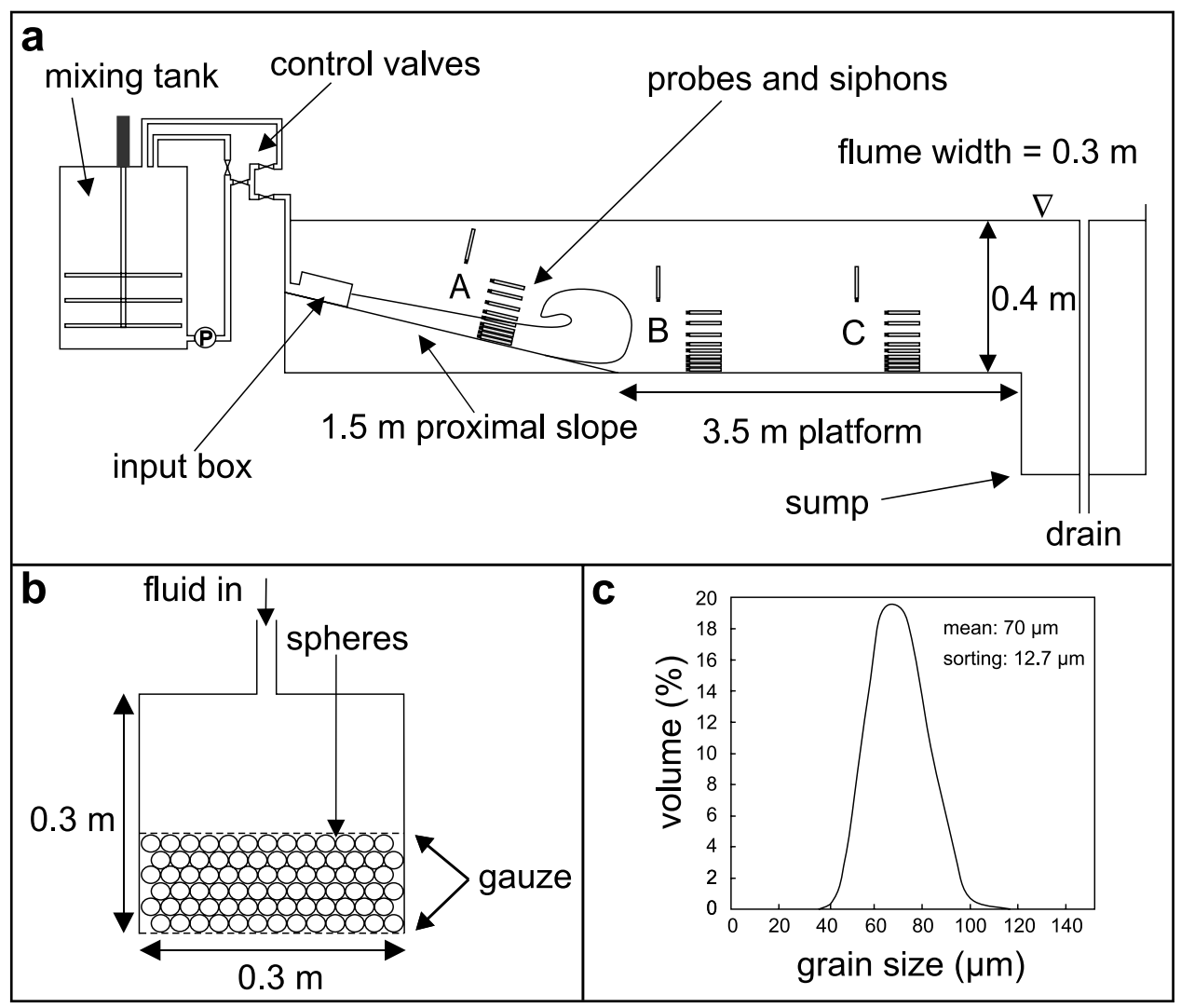

Figure 1. (a) Schematic drawing showing the experimental setup and measurement Locations A, B, and C. The saline solutions and sediment suspensions were mixed in the mixing tank and pumped into the flume through the input box producing a STC (sustained turbidity current). Four proximal slopes $\left(0^{\circ}, 3^{\circ}\right.$, $6^{\circ}$, and $9^{\circ}$ ) that abruptly changed to a horizontal platform were used. The three measurement locations were (A) on the slope, (B) at the slope break, and (C) downstream from the slope break. Ambient water depth was kept constant by means of an overflow pipe located at the downstream end of the flume. Upstream facing Ultrasonic Doppler Velocity Profiler (UDVP) probes were arranged in a $9 \times 1$ array, alongside an array of nine siphon tubes also pointing upstream. P, pump; $\nabla$, water level. (b) The input box. Spherical plastic beads were used to reduce momentum and evenly spread the fluid across the full width of the box. The fluid then exited the box through gauze at the front. (c) Grain size distribution of the Ballotini used in the turbidity runs $\left(\rho=2500 \mathrm{~kg} \mathrm{~m}^{-3}\right)$.

in saline and particulate currents, and Macias et al. [1998] and Woods et al. [1998] used saline density currents seeded with various types of particle to model the deposition of volcanic lithic-breccias and ashes interacting with topography.

[4] The gradient of the bed slope is an important control on flow structure and evolution. Ellison and Turner [1959] originally demonstrated how steeper slopes promote increased mixing at the interface between saline density currents and the ambient fluid. The processes of autosuspension (where turbulence generation in a flow maintains a particulate suspension without any external supply of energy) is favored by steep slopes [Pantin, 2001]. Also, natural turbidity currents often flow across gradient changes at the base of slope; these affect both turbulence structure and deposit character in experimental turbidity currents [Mulder and Alexander, 2001; Gray et al., 2005].

[5] This paper attempts a systematic detailed comparison of the turbulence structure and flow evolution of dynamically similar saline density and turbidity currents. A series of experiments were designed to compare the turbulent velocity structure of saline density and turbidity currents that flow down various slopes onto a horizontal floor. Three main influences on the constant discharge flows are (1) the nature of the density contrast and the effect of sediment in the flow, (2) the effect of slope, and (3) the effect of the slope break. The experiments are useful analogues for a range of geophysical density current and provide measurements of turbulence parameters that may be useful for numerical models and future experimental and field studies of particulate transport and deposition in such flows and in the interpretation of their deposits.

\section{Experimental Setup and Procedure}

[6] In a $6 \mathrm{~m}$ long flume tank ( $0.3 \mathrm{~m}$ wide, $0.5 \mathrm{~m}$ deep) a rigid PVC ramp of slope $0^{\circ}, 3^{\circ}, 6^{\circ}$ or $9^{\circ}$ terminated abruptly on the flat tank floor (Figure 1a). A saline solution or sediment suspension with density of $1014 \mathrm{~kg} \mathrm{~m}^{-3}$ was agitated in a $0.2 \mathrm{~m}^{3}$ mixing tank and discharged into the flume at $1 \times 10^{-3} \mathrm{~m}^{3} \mathrm{~s}^{-1}\left( \pm 0.01 \times 10^{-3} \mathrm{~m}^{3} \mathrm{~s}^{-1}\right)$. The input pipe fed into a box partially filled with large plastic spheres in order to dissipate momentum from the pipe and spread 
Table 1a. Distances in Meters From Input Box to Measurement Locations, Taken Centrally Along the Bed for All Slopes

\begin{tabular}{cccc}
\hline Location & $\mathrm{A}$ & $\mathrm{B}$ & $\mathrm{C}$ \\
\hline $0^{\circ}$ & 0.822 & 1.575 & 2.391 \\
$3^{\circ}$ & 0.811 & 1.522 & 2.409 \\
$6^{\circ}$ & 0.799 & 1.591 & 2.479 \\
$9^{\circ}$ & 0.766 & 1.576 & 2.126 \\
\hline
\end{tabular}

the fluid evenly across the width of the flume. The flows exited the box through a metal gauze covered slot with height of $0.04 \mathrm{~m}$ (Figure 1b). Either salt or spherical glass ballotini (mean diameter $70 \mu \mathrm{m}$, Figure 1c) provided the density contrast between the input fluid and the ambient water (of same temperature) in the tank. The ambient water depth of $0.4 \mathrm{~m}$ (measured on the platform) was maintained using an overflow pipe. Following the passage of the flow front, currents flowed in a steady state for 3-4 min; the total flow duration being limited by the size of the mixing tank and length of the flume.

[7] An array of 10 Ultrasonic Doppler Velocity Profiler (UDVP) probes was used to measure two-component velocities $(u$ and $v)$ at nine points above the bed (Figure 1). UDVP probes emit bursts of ultrasound, dependent on the transducer frequency $(4 \mathrm{MHz})$ then listen for any Doppler shift of the signal reflected by particles in the flow. This allows the velocity of particles at a point to be determined [Best et al., 2001]. The $u$-velocity (streamwise) component was measured using probes aligned parallel to the bed, sampling upstream along the centerline of the flume to minimize any flow field disturbance. A single probe sampled vertically down toward the bed to record the $v$-velocity (bed-normal) component. This probe array was used at three locations for each slope angle: (A) on the slope, (B) at the slope break, and (C) downstream from the slope break (Tables 1a and 1b). Six runs with identical input discharge (three with saline density currents and three with turbidity currents) were undertaken for each slope. To avoid generating artifacts owing to equipment repositioning during a single run, the array was deployed at a different location (A, $\mathrm{B}$, and $\mathrm{C}$ ) in identical duplicate runs (Figure 1).

[8] Each UDVP probe was $8 \mathrm{~mm}$ in diameter and velocity measurements were simultaneously collected in 128 bins along the probes' axis. When multiple probes were used, the UDVP collected data from one probe at a time and probes

Table 1b. Heights Above Bed for the 10 Probes $^{\mathrm{a}}$

\begin{tabular}{lc}
\hline Probe & Height, mm \\
\hline 1 & 5 \\
2 & 15.5 \\
3 & 26 \\
4 & 36.5 \\
5 & 48 \\
6 & 65 \\
7 & 90 \\
8 & 130 \\
9 & 180 \\
10 & 220 \\
\hline
\end{tabular}

${ }^{\text {a }}$ Probes number sequentially starting with the lowermost upstream sampling probe and finishing on the downward sampling probe.
Table 2. Ultrasonic Doppler Velocity Profiler and Array Parameters $^{\mathrm{a}}$

\begin{tabular}{ll}
\hline \multicolumn{1}{c}{ Parameter } & \multicolumn{1}{c}{ Value } \\
\hline Transducer ultrasound frequency & $4 \mathrm{MHz}$ \\
Pulse repetition frequency & $1685 \mathrm{~Hz}$ \\
Transducer diameter & $5 \mathrm{~mm}$ \\
Probe diameter & $8 \mathrm{~mm}$ \\
Beam divergence (1/2 angle) & $2.2^{\circ}$ \\
Measurement window & $40.52-229.96 \mathrm{~mm}$ \\
Bin length & $1.48 \mathrm{~mm}$ \\
Minimum bin diameter & $3.11 \mathrm{~mm}$ \\
Maximum bin diameter & $17.66 \mathrm{~mm}$ \\
Velocity resolution & $1.4 \mathrm{~mm} \mathrm{~s}^{-1}$ \\
Maximum velocity & $180.1 \mathrm{~mm} \mathrm{~s}^{-1}$ \\
Ultrasound velocity & $1480 \mathrm{~m} \mathrm{~s}$ \\
Mean sampling time per profile & $17 \mathrm{~ms} \mathrm{~s}^{-1}$ \\
Delay between sampling profiles & $15 \mathrm{~ms}$ \\
Array sampling time & $0.32 \mathrm{~s}$ \\
Array sampling frequency & $3.125 \mathrm{~Hz}$ \\
\hline
\end{tabular}

${ }^{\mathrm{a}}$ The beam divergence is the spread of the ultrasound beam with distance away from the transducer, giving a minimum and maximum bin diameter at the ends of the measurement window. The ultrasound velocity, pulse repetition frequency (adjusted depending on the number of particles in the flow), and delay between profiles (to stop signal crossover between profiles) were optimized to suit the present experimental requirements, the maximum velocity and velocity resolution being the same in each run.

were switched on sequentially around the array, giving a sampling frequency of $3.125 \mathrm{~Hz}$ for each recorded velocity time series. By adjusting UDVP parameters the sampling window position and the velocity range and resolution of the probes can be varied, although these were necessarily the same for each probe (Table 2). To minimize loss of resolution due to smaller magnitude bed-normal velocities, discharge and UDVP parameters were optimized giving adequate results for both velocity components. A small volume of potassium permanganate was added to the brines to give visible contrast and to produce an adequate response from the UDVP probes.

[9] An array of nine $8 \mathrm{~mm}$ diameter siphon tubes was positioned $0.08 \mathrm{~m}$ to the side of the UDVP probes, minimizing interference between the equipment and UDVP measurement windows. Fluid samples were taken simultaneously from all tubes during the quasi-steady period of each run. Siphon samples were used to calculate a mean density profile for both flow types at each measuring location. For saline density-current runs, density profiles were obtained using a conductivity meter that was calibrated using standard saline solutions at room temperature. For turbidity current runs, samples were filtered, dried and weighed to determine the volume concentration of particles and the sample density. Deposits were sampled using a siphon method (where sediment is sucked from the bed over a fixed area) to determine the mass distribution. A video camera recorded the visual appearance of the flows in side view.

\section{General Flow and Deposit Characteristics 3.1. Flow Morphology}

[10] Each flow developed a leading head and trailing body within a few centimeters of exiting the input box (Figure 2). Lobes and clefts disrupted the frontal boundary and a turbulent wake formed behind the head that dissipated 


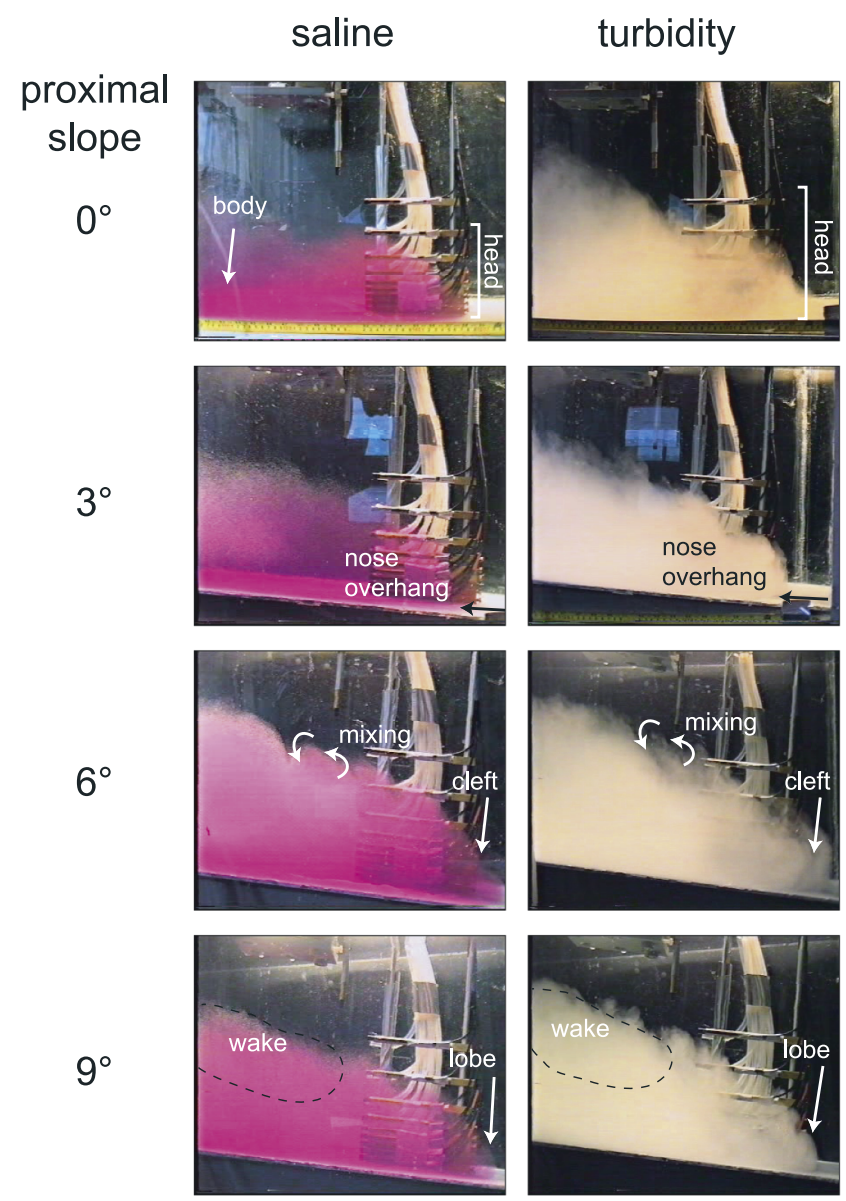

Figure 2. Still frames taken from video recordings showing heads of saline and turbidity flows at Location A. The UDVP and siphon arrays are visible within the heads. Disturbances occur at the ambient fluid boundary. The turbulent wake is indicated for the $9^{\circ}$ cases. Heads of turbidity flows are more turbulent and have more diffuse mixing boundaries than equivalent saline flows; however, they are comparable in shape and size.

with time following the passage of the head. All currents were turbulent and subcritical at all locations with deposition to the bed from the turbidity flows over the full run out distance (Table 3). Heads of both flow types were similar in shape on each slope at each location (Figure 2). The head size of both flow types (measured on video time-frame stills) increased with slope at Location A and this size increase was more obvious for saline flows than turbidity flows, as sediment settling from the wake obscured the trailing head boundary (Figure 2). Head size increased downstream for both flow types; however, turbidity flow heads were larger at Location $\mathrm{C}$ than equivalent saline ones.

[11] Saline flow bodies had similar thickness (to within $30 \%$ ) and turbidity flow bodies decreased in thickness at Location A with increasing slope (Table 3). Generally, flow thickness increased downstream in all runs and turbidity flow bodies were thicker than those of equivalent saline flows (Table 3). There was a sharp interface between the brine and ambient fluid, while a dispersed
Table 3. General Flow Parameters for Each Slope at Locations A, $\mathrm{B}$, and $\mathrm{C}^{\mathrm{a}}$

\begin{tabular}{|c|c|c|c|c|c|c|}
\hline \multirow[b]{2}{*}{$\underline{\text { Slope }}$} & \multicolumn{3}{|c|}{ Saline } & \multicolumn{3}{|c|}{ Turbidity } \\
\hline & $\mathrm{A}$ & $\mathrm{B}$ & $\mathrm{C}$ & A & $\mathrm{B}$ & $\mathrm{C}$ \\
\hline \multicolumn{7}{|c|}{$R e=\frac{U_{d} h}{v}$} \\
\hline $0^{\circ}$ & 1800 & 2000 & $2700^{2}$ & 5000 & 5900 & 5400 \\
\hline $3^{\circ}$ & 4000 & 4800 & 4800 & 7100 & 5800 & 6900 \\
\hline $6^{\circ}$ & 4700 & 5500 & 7000 & 6700 & 6700 & 6700 \\
\hline $9^{\circ}$ & 5400 & 6900 & 7400 & 6600 & 6700 & 7200 \\
\hline \multicolumn{7}{|c|}{$F r=\frac{U_{d}}{\left(h g^{\prime} \cos \theta\right)^{\frac{1}{2}}}$} \\
\hline $0^{\circ}$ & 0.4 & 0.2 & 0.2 & 0.21 & 0.36 & 0.30 \\
\hline $3^{\circ}$ & 0.7 & 0.4 & 0.3 & 0.34 & 0.29 & 0.25 \\
\hline $6^{\circ}$ & 0.8 & 0.5 & 0.3 & 0.58 & 0.28 & 0.31 \\
\hline $9^{\circ}$ & 0.8 & 0.6 & 0.3 & 0.63 & 0.43 & 0.27 \\
\hline \multicolumn{7}{|c|}{$h\left(\mathrm{~m} \times 10^{-3}\right)$} \\
\hline $0^{\circ}$ & 57 & 95 & 111 & 170 & 135 & 143 \\
\hline $3^{\circ}$ & 69 & 113 & 123 & 156 & 152 & 188 \\
\hline $6^{\circ}$ & 67 & 105 & 168 & 106 & 172 & 161 \\
\hline $9^{\circ}$ & 75 & 107 & 164 & 99 & 129 & 184 \\
\hline \multicolumn{7}{|c|}{$U_{\max }\left(m s^{-1} \times 10^{-3}\right)$} \\
\hline $0^{\circ}$ & 46 & 53 & 58 & 94 & 106 & 93 \\
\hline $3^{\circ}$ & 105 & 133 & 110 & 110 & 104 & 80 \\
\hline $6^{\circ}$ & 140 & 161 & 129 & 125 & 122 & 89 \\
\hline $9^{\circ}$ & 148 & 173 & 134 & 135 & 129 & 92 \\
\hline \multicolumn{7}{|c|}{$\left(m s^{-1} \times 10^{-3}\right)$} \\
\hline $0^{\circ}$ & 36 & 24 & 28 & 34 & 50 & 43 \\
\hline $3^{\circ}$ & 66 & 48 & 44 & 52 & 43 & 42 \\
\hline $6^{\circ}$ & 81 & 60 & 48 & 72 & 45 & 47 \\
\hline $9^{\circ}$ & 81 & 74 & 52 & 76 & 59 & 45 \\
\hline
\end{tabular}

${ }^{\mathrm{a}} \mathrm{Re}$, Reynolds number; $\mathrm{Fr}$, Froude number; $h$, flow height or thickness; $U_{\max }$, maximum-mean $u$ velocity; $U_{d}$, depth-averaged velocity, where $g^{\prime}=$ $g\left(\rho_{c}-\rho_{a}\right) / \rho_{a}, v$ is the kinematic viscosity taken at $15^{\circ} \mathrm{C}, g$ is the gravitational acceleration constant $\left(9.81 \mathrm{~m} \mathrm{~s}^{-2}\right), \theta$ is the slope, and $\rho_{c}$ and $\rho_{a}$ are current and ambient densities.

mixing layer marked the interface of turbidity flows (Figure 3). Wave-like eddies occurred at the ambient fluid interface of both flow types. Mixing appeared more vigorous on steeper slopes in both cases although the

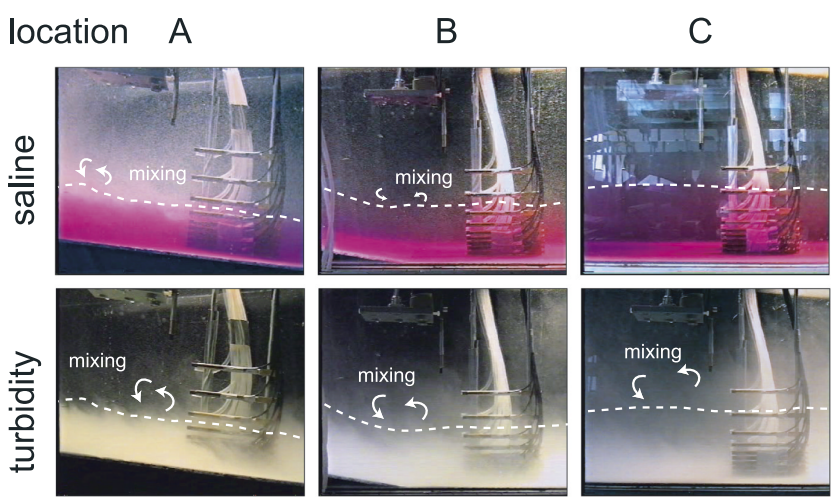

Figure 3. The bodies of the $9^{\circ}$ flows at all locations. The dashed line approximately indicates the top of the body. Saline flows have a sharper ambient fluid boundary than turbidity flows. Turbidity flow bodies have diffuse and expanded mixing layers disturbed by Kelvin-Helmholtz billows. Disturbances appear limited to uppermost parts of saline flows but stretch down into the lower body in turbidity flows. Both flow types are seen to expand from Locations A to C. 


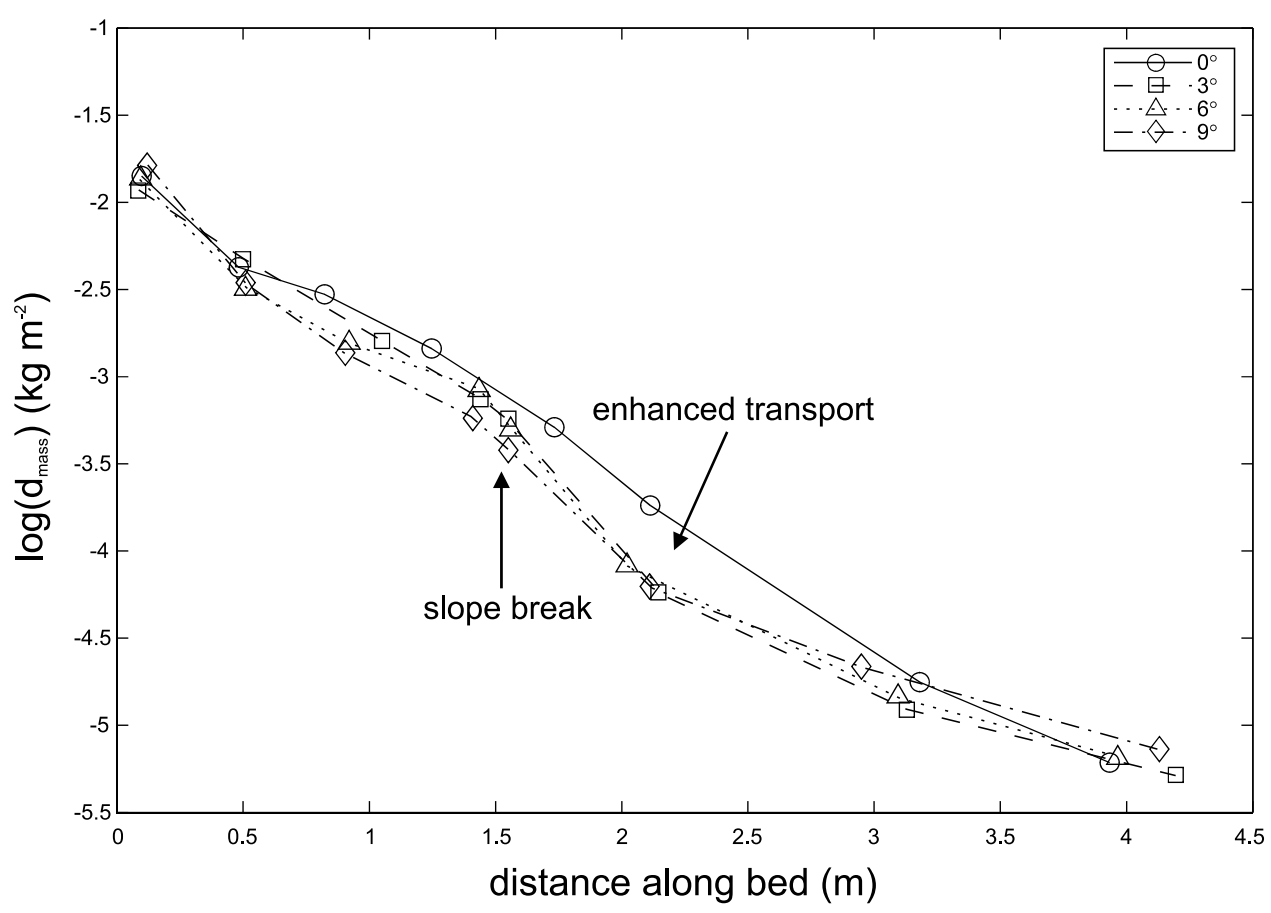

Figure 4. Profiles of deposit mass per unit bed area $\left(d_{\text {mass }}\right)$ with distance downstream. Deposit mass decreases downstream of the slope break compared with the $0^{\circ}$ case.

frequency of eddy formation and break-up was less for saline flows than turbidity flows for a given slope (Figure 3).

\subsection{Deposition}

[12] The deposit mass from turbidity flows decreased exponentially with distance downstream (Figure 4). Flows on slopes have reduced deposit mass at the slope break, indicating increased sediment transport (reduced deposition) across the slope break [cf. Gray et al., 2005]. There appears to be no variation in the length or thickness of the "enhanced transport" region with proximal slope angle (Figure 4). There is some indication that flows on steeper proximal slopes deposit less sediment on the slope and more on the tank floor compared with shallower slope flows.

\subsection{Velocity Profiles}

[13] Velocities were averaged over the duration of the passage of the quasi-steady body of the flow to produce mean velocities. Mean at-a-point $u$ and $v$ velocities ( $U$ and $V$ ) were used to construct profiles; these were normalized by division by $U_{\max }$ to examine similarity between profiles (Figure 5). Mean $u$ (streamwise) velocity profiles of all of the flows fit a composite log-Gaussian curve [cf. Altinakar et al., 1996; Kneller et al., 1999] (for example, Figure 5a). The $0^{\circ}$ saline flow at Location A differs slightly in the Gaussian part of the profile from the other flows at this location (Figure 5a). At Location C, $U$ velocity profiles are similar in shape for each flow (Figure 5a). The slightly negative values of $U$ toward the top of the Gaussian part of the flows arise primarily from a weak counter flow in the upper ambient fluid related to low ambient water depth [cf. Huppert and Simpson, 1980].

[14] Normalized mean $v$ (bed-normal) velocity profile shape varies with flow type, slope and location (Figure $5 \mathrm{~b}$ ). Excluding the $0^{\circ}$ cases, $V$ profiles are of similar shape for turbidity and saline flows although the former have somewhat steeper gradients (Figure 5b). $V$ increases with height to a peak $\left(V_{\max }\right)$ above the level of $U_{\max }$, and then decreases toward zero or becomes negative. Both flows on the zero slope at Locations $\mathrm{A}$ and $\mathrm{C}$ have lower $V$ magnitudes than flows on steeper slopes, and at Location A, $V$ profiles have a different shape (Figure $5 b$ ).

\subsection{Layer Velocity Structure}

[15] Depth-averaged velocities $\left(U_{d}\right)$ were calculated by integrating $U$ velocity profiles from the bed to the height $(h)$ at which $U$ tends to zero at the top of the flow, and dividing by $h$ (Table 3 ). $U_{d}$ increases with slope at Location A for both flow types, and at Locations $\mathrm{B}$ and $\mathrm{C}$ for saline flows (Table 3 and Figure 6a). Both flow types decelerate with distance downstream, although saline flows with $3^{\circ}$ and $6^{\circ}$ proximal slopes decelerate slightly more between Locations $\mathrm{A}$ and $\mathrm{B}$ than between $\mathrm{B}$ and $\mathrm{C}$. Turbidity flows propagate slower downstream than equivalent saline flows due to buoyancy reduction by sediment deposition (Figures 6a and $6 \mathrm{~b}$ and Table 3). However, at Location C, turbidity current deceleration is less than for equivalent slope saline flows and $U_{d}$ velocities converge, despite the more rapid downstream propagation of saline flows (Figure $6 \mathrm{~b}$ and Table 3). There is a general trend for greater deceleration of turbidity flows initiated on slopes between Locations $\mathrm{A}$ and $\mathrm{B}$ than between $\mathrm{B}$ and $\mathrm{C}$, and $U_{d}$ magnitudes of all turbidity flows are similar at Locations $\mathrm{B}$ and $\mathrm{C}$. The $0^{\circ}$ saline flows decelerate between Locations $\mathrm{A}$ and $\mathrm{B}$ and accelerate slightly between $\mathrm{B}$ and $\mathrm{C}$, while the $0^{\circ}$ turbidity flows accelerate between Locations $\mathrm{A}$ and $\mathrm{B}$ and decelerate slightly between B and C.

[16] The maximum mean $u$ velocity $\left(U_{\max }\right)$ increases with slope at Locations A and B, a trend that is more pronounced 


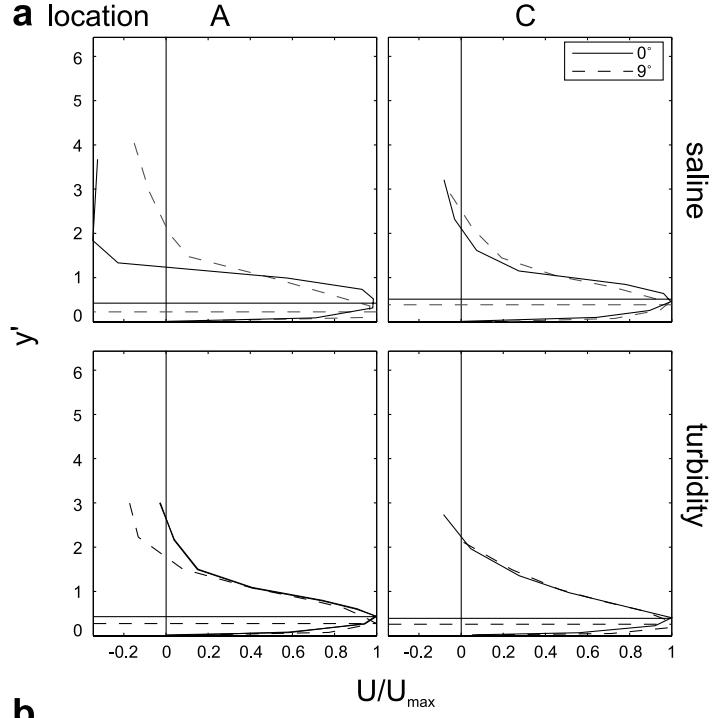

b

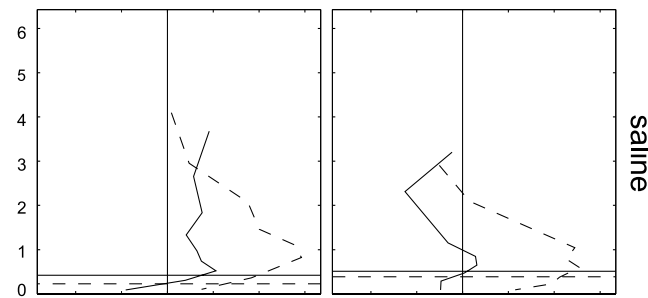

$>$

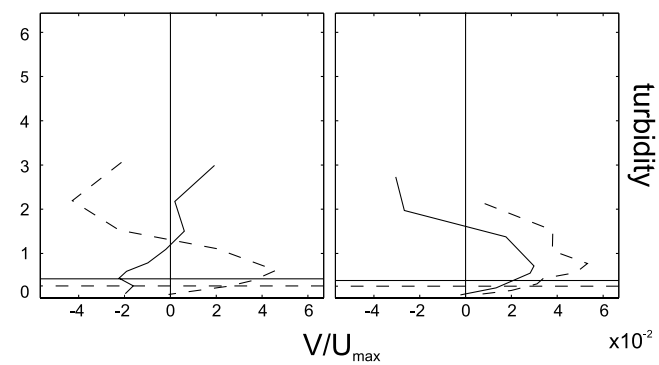

Figure 5. (a) Normalized mean $u$-velocity profiles $(U)$ for both flow types on the $0^{\circ}$ and $9^{\circ}$ slopes at Locations A and C. Horizontal lines indicate the height of maximum mean $u$ velocity $\left(U_{\max }\right)$, and vertical lines indicate zero velocity. Profiles have a log-Gaussian shape. Approximately two velocity and siphon sample points were in the logarithmic part of the flows (below $U_{\text {max }}$ ), and seven were in the Gaussian part (above $U_{\max }$ ). Mean velocities were normalized by dividing by $U_{\max }$, and heights $(y)$ were normalized by dividing by the height at which $U$ drops to half $U_{\max }$ (the $y_{1 / 2}$ value) [cf. Buckee et al., 2001] giving $y^{\prime}$. (b) Normalized mean $v$-velocity profiles $(V)$ for the same flows as in Figure $5 \mathrm{a}$, with $U_{\max }$ heights indicated. Turbidity flows have steeper gradients of $V$ compared with saline flows at Locations $\mathrm{A}$ and $\mathrm{C}$.

for saline flows than turbidity flows (Table 3 ). $U_{\max }$ has similar magnitude in saline cases on all nonzero slopes at Location $\mathrm{C}$ and at Locations $\mathrm{B}$ and $\mathrm{C}$ in turbidity cases. $U_{\max }$ is significantly lower for the $0^{\circ}$ saline flows at all locations compared with flows on other slopes. Layeraveraged velocities were calculated from the bed up to $U_{\max }$ and between $U_{\max }$ and the top of the flow, separating the lower logarithmic $\left(U_{d \mathrm{log}}\right)$ and upper Gaussian $\left(U_{d \text { Gaus }}\right)$ parts of the flows. For each layer the velocity change between Locations $\mathrm{A}$ and $\mathrm{B}$, and Locations $\mathrm{B}$ and $\mathrm{C}$ was calculated for each flow by taking the velocity change between locations as a percentage of the velocity at the first location (A or B). Thus the magnitude of acceleration or deceleration and the difference between layers could be assessed (Table 4).

[17] Saline flows exhibit a similar change of $U_{d l o g}$ between Locations $\mathrm{A}$ and $\mathrm{B}$, however deceleration of $U_{d \text { Gaus }}$ decreases between the same locations with increasing proximal slope (Table 4). Between Locations B and C both layers of the saline flows (apart from the $0^{\circ}$ case) decelerate; however, the Gaussian layers of flows with steeper proximal slopes slow proportionally more than the logarithmic layers. For turbidity flows there is no clear trend in the change of $U_{d \log }$ or $U_{d \mathrm{Gaus}}$ between Locations A and B. Between Locations B and C, $U_{d l o g}$ decelerates independently of slope and there is no clear trend in the change of $U_{d \mathrm{Gaus}}$. Decelerations are greater for the logarithmic layer than the Gaussian layer, in contrast to saline flow data.
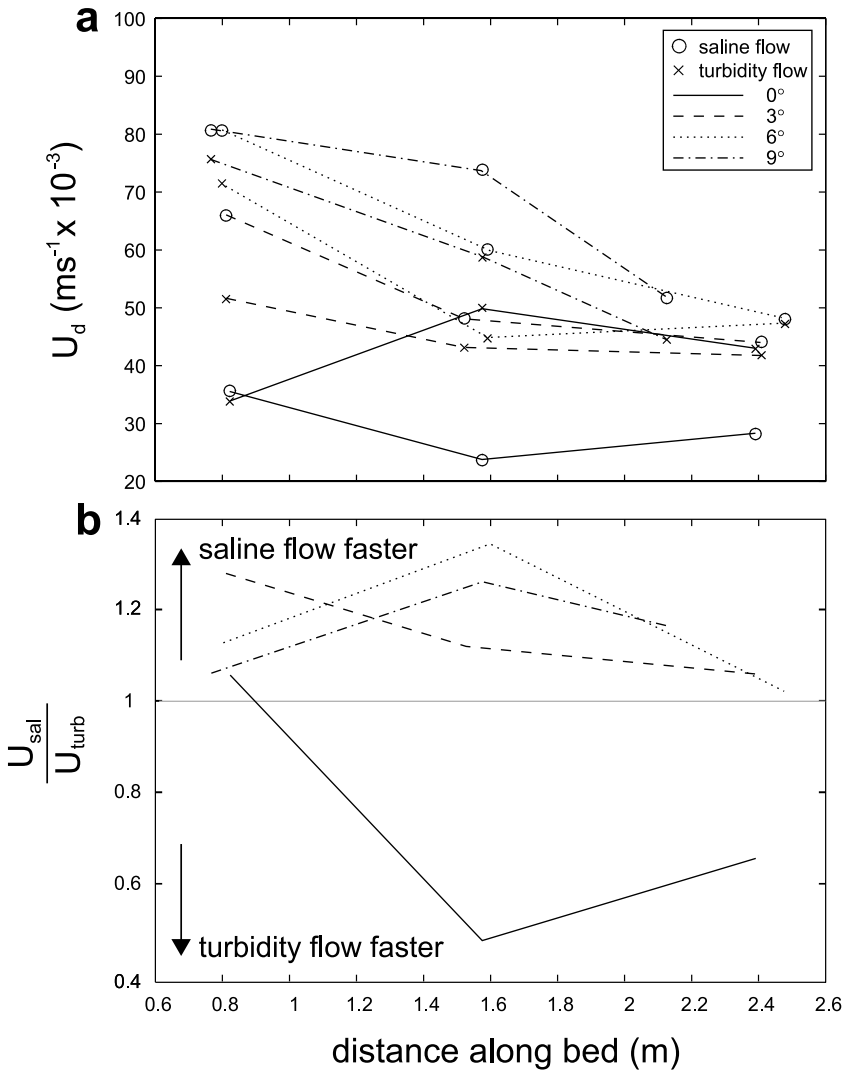

Figure 6. (a) Depth-averaged velocity $\left(U_{d}\right)$ magnitudes plotted against distance downstream. Saline flows are generally faster than equivalent slope turbidity flows at upstream locations, although $U_{d}$ magnitudes tend to converge at Location $\mathrm{C}$ for all flows. (b) $U_{d}$ expressed as ratios of saline to turbidity flows $\left(U_{s a l} / U_{t u r b}\right)$ plotted against downstream distance. When $U_{\text {sal }} / U_{\text {turb }}>1$, saline flows are faster; when $U_{\text {sal }} / U_{t u r b}<1$, turbidity flows are faster. At downstream locations, $U_{\text {sal }} / U_{\text {turb }}$ approaches 1 for all flows, indicating that either saline flows are slowing faster than turbidity flows or the rate of layer-averaged streamwise velocity decay is less for turbidity flows than equivalent slope saline flows. 
Table 4. Velocity Change in Percent for Each Layer Between Locations A and B, and Locations B and C for Each Flow ${ }^{\text {a }}$

\begin{tabular}{ccccc}
\hline & \multicolumn{2}{c}{ Saline } & \multicolumn{2}{c}{ Turbidity } \\
\cline { 2 - 5 } \cline { 4 - 5 } Slope & A-B & B-C & A-B & B-C \\
\hline & 11 & Logarithmic Layer & & \\
$0^{\circ}$ & 14 & 13 & 10 & -13 \\
$3^{\circ}$ & 9 & -18 & -9 & -24 \\
$6^{\circ}$ & 18 & -25 & 7 & -25 \\
$9^{\circ}$ & & -2 & -28 \\
& & Gaussian Layer & & \\
$0^{\circ}$ & -47 & 20 & 62 & -15 \\
$3^{\circ}$ & -32 & -15 & -10 & -3 \\
$6^{\circ}$ & -30 & -24 & -41 & 6 \\
$9^{\circ}$ & -12 & -36 & -23 & -25 \\
\hline
\end{tabular}

${ }^{\mathrm{a}}$ Calculations were determined by taking the velocity change between locations as a percentage of the velocity at the first location (A or B).

\subsection{Density Profiles and the Gradient Richardson} Number

[18] Generally at all locations saline flows have higher densities on gentler proximal slopes at normalized heights $y^{\prime}<1$. At $y^{\prime}>1$ the opposite is true (Figure 7a). For turbidity flows there is a trend of increasing density with increasing slope at Location A, with no difference at Location C. The downstream decrease of turbidity flow density at all levels from Locations $\mathrm{A}$ to $\mathrm{C}$ due to sediment deposition is in marked contrast to the much smaller downstream decrease below $y^{\prime}=1$ for saline flows.

[19] To assess stability of the mixing zone, gradient Richardson numbers were calculated using,

$$
R i_{g}=\frac{-\frac{g}{\rho} \frac{\partial \rho}{\partial y}}{\left(\frac{\partial U}{\partial y}\right)^{2}},
$$

where $\rho$ is fluid density (Figure $7 \mathrm{~b}$ ). When $R i_{g}<0.25$, small perturbations grow and flows mix [Miles, 1961]. The profiles resemble published results, showing maxima around the height of $U_{\max }$ and minima in the lower logarithmic and mid-lower Gaussian parts of the flow where velocity and density gradients are steepest [Stacey and Bowen, 1988; Buckee et al., 2001]. For saline flows, the minimum value of $R i_{g}$ in the Gaussian part of the flow has been found to decrease with increasing slope [Ellison and Turner, 1959]. The narrow vertical interval of $R i_{g}<0.25$ between $y^{\prime}=$ c. $1.5-2.25$ vanishes almost entirely downstream from A to $\mathrm{C}$ (Figure $7 \mathrm{~b}$ ). There is little difference in $R i_{g}$ between slopes for turbidity flows, with minimum values always less than saline flows and varying little downstream. For all these flows, $R i_{g}<0.25$ above $y^{\prime}=0.5$ and mixing occurs at all upper-body ambient-fluid interfaces (Figure 7b). Both flow types are well mixed in the lower logarithmic layer $\left(R i_{g}<0.25\right.$ at $\left.y^{\prime}<0.2\right)$ with little mixing between $y^{\prime}=$ c. $0.2-0.5$ where velocity gradients are the gentlest.

\subsection{Discussion: Flow Structure, Mixing, and Slope Adjustment}

[20] Mixing occurs at the frontal boundary of the head of density currents and along the top of the body. Lobes and clefts arise from a vigorous linear instability produced by unstable stratification between the leading edge and the stagnation point ahead of the front [Härtel et al., 2000]. Larger heads associated with steep proximal slopes arise as increased mixing or increased inflow from the body occurs [Middleton, 1966; Britter and Linden, 1980; Siegenthaler
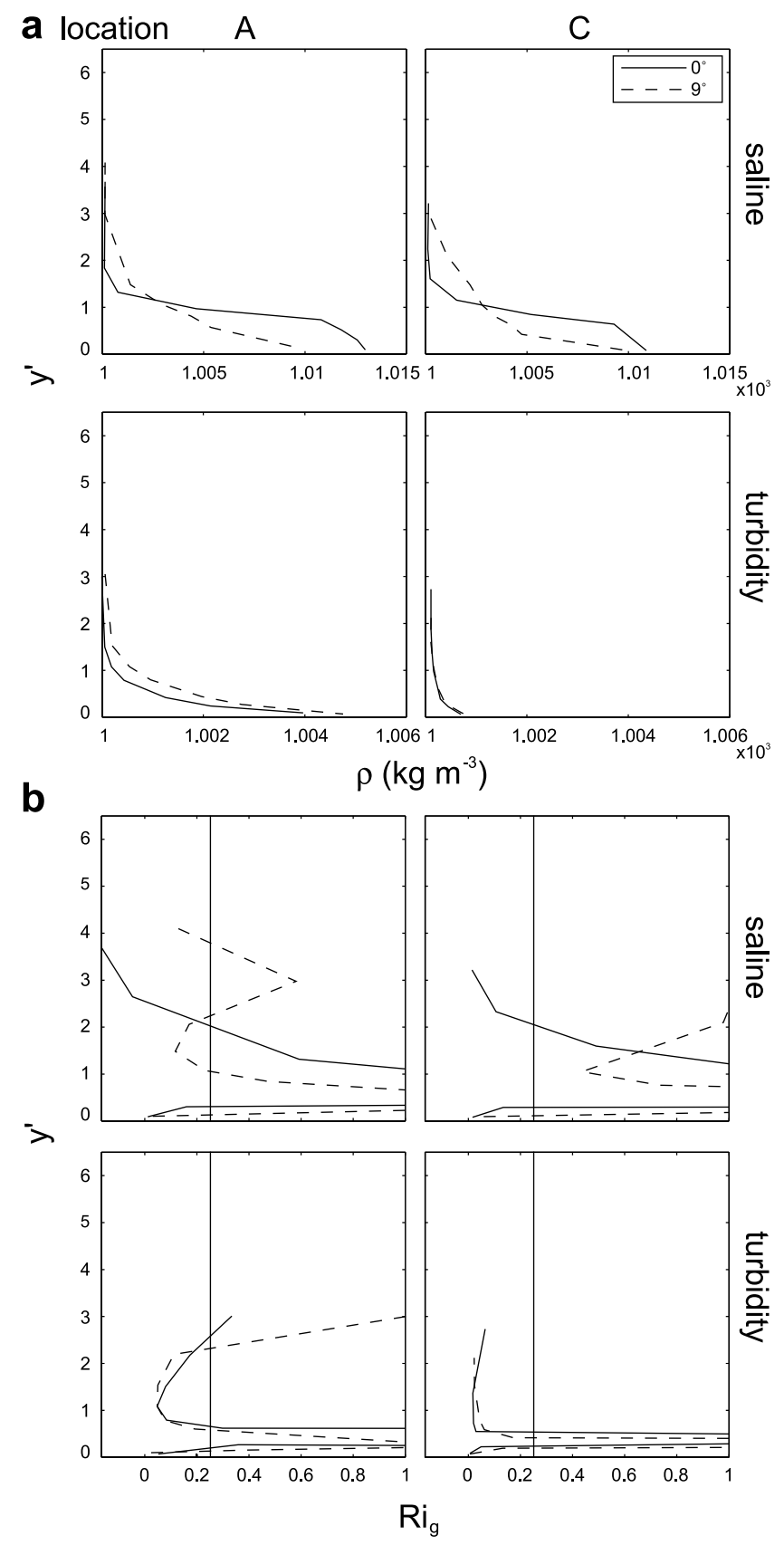

Figure 7. (a) Profiles of current density for both flow types on $0^{\circ}$ and $9^{\circ}$ slopes at Locations $\mathrm{A}$ and C. Turbidity flows have differently shaped density profiles compared with saline flows, owing to sediment settling. (b) The gradient Richardson number plotted against normalized height for the same flows as in Figure $7 \mathrm{a}$. Peaks in $R i_{g}$ occur in both the logarithmic and Gaussian parts of the flows. $R i_{g}$ tends to infinity at the level of $U_{\max }$. Profiles are truncated at $R i_{g}=1$, because mixing is only significant when $R i_{g}<$ 0.25 (shown by the vertical lines). Turbidity flows are able to mix much more readily than saline flows. 
and Buhler, 1985]. On steep slopes direct entrainment is more significant than on gentler slopes, because of an increase in disturbances at the frontal boundary [Britter and Linden, 1980, Figure 2]. The heads of turbidity flows expanded downstream more than saline flows. This extra growth is due to greater slowing and thickening of turbidity flows due to buoyancy loss on the horizontal tank floor, where inflow from the body is limited by the zero slope condition.

[21] Mixing with ambient fluid along the top of the body arises as turbulent kinetic energy is transferred to potential energy through shear-generated Kelvin-Helmholtz eddies. In a density current this dilution reduces the driving buoyancy force. Little entrainment occurs in subcritical saline flows, although for higher $R i_{g}$ flows weaker external eddies and waves may occur [Parker et al., 1987; Strang and Fernando, 2001]. Saline flow mixing depends on slope, with a band of $R i_{g}<0.25$ in the upper Gaussian layer broadening with slope and Gaussian layer deceleration decreasing with slope [cf. Ellison and Turner, 1959] (Figure $7 \mathrm{~b}$ and Table 4). However, turbidity flows mix more than saline flows $\left(R i_{g}<0.25\right.$ above $\left.y^{\prime}=0.5\right)$ and decelerate less on gentle or zero slopes (Table 3 and Figures 6 and $7 \mathrm{~b}$ ). For zero slope saline flows, $R i_{g}$ becomes $<0.25$ only at the very top of the flow (ignoring the well mixed logarithmic layer). The slightly different $U$ velocity profile (Figure $5 \mathrm{a}$ ) suggests that on zero slopes saline flows are unable to adjust rapidly from initial input conditions. In contrast, turbidity flows are able to adjust their flow structure independently of slope; hence mixing has no dependence on slope.

\section{Turbulence Structure}

[22] The two-dimensional Reynolds stress, $\tau_{i j}$, for unit volume of incompressible Newtonian fluid may be separated into three components [e.g., Tritton, 1988],

$$
\begin{gathered}
\tau_{x x}=-\rho \overline{u^{\prime} u^{\prime}}, \text { for } i=1 \text { and } j=1, \\
\tau_{y y}=-\rho \overline{v^{\prime} v^{\prime}}, \text { for } i=2 \text { and } j=2, \\
\tau_{y x}=-\rho \overline{u^{\prime} v^{\prime}}, \text { for } i=1 \text { and } j=2,
\end{gathered}
$$

where $\rho$ is fluid density, $u^{\prime}=u_{i}-U$ and $v^{\prime}=v_{i}-V$ for each instantaneous velocity in a time series. The first two components are normal stresses; the third component is a shear stress. Reynolds stresses arise from the nonuniform turbulent acceleration term in the Navier-Stokes equations and reflect the stresses imposed by turbulent velocity fluctuations on the mean flow. Any gradient in $\tau_{i j}$ produces a net acceleration as fluid momentum is exchanged in turbulent mixing. The turbulent kinetic energy per unit volume $T_{k e}$ may be written as

$$
T_{k e}=\frac{1}{2} \rho\left(\overline{u^{\prime 2}}+\overline{v^{\prime 2}}\right)
$$

Both $T_{k e}$ and the Reynolds stresses calculated for the experiments were normalized by dividing by $U_{\max }{ }^{2}$ determined for each flow type, slope and location, and by $\rho$ at each measurement point in the bed-normal profiles.

\subsection{Variation in Turbulence Structure With Flow Type and Slope}

[23] Normalized velocity profiles, three components of Reynolds stress and turbulent kinetic energy calculated from saline and turbidity flow data on the $3^{\circ}$ and $9^{\circ}$ slopes at Location A are shown in Figure 8. The normalized mean $u$ velocity curves are nearly identical log-Gaussian profiles, with $U_{\max }$ lines at approximately the same $y^{\prime}$, but the normalized mean $v$-velocity curves are significantly different (Figure 8). Except for positions below $U_{\max }$, the saline flow profiles have almost no $V$ gradient, with near zero or slightly positive magnitudes. The $3^{\circ}$ and $9^{\circ}$ slope turbidity flow profiles show positive gradients up to inflections at $c$. $y^{\prime}=0.4$ and $y^{\prime}=0.6$ respectively, with both flows having a strong negative gradient of $V$ above.

[24] The streamwise Reynolds normal stress component $\left(\tau_{x x}\right)$ has a similar profile shape for both flow types on both slopes, with peaks at $c . y^{\prime}=1$. In the $3^{\circ}$ slope cases the turbidity flow profile has a larger magnitude and more accentuated peak than the saline flow profile. In the $9^{\circ}$ slope cases it is the saline flow that has the larger $\tau_{x x}$ peak. There is substantial difference between the vertical Reynolds normal stress component $\left(\tau_{y y}\right)$ of each flow type on both slopes. The saline flow profiles are flat with no significant gradients. A distinct peak occurs in the turbidity flow profiles at $y^{\prime}=1$. The peak $\tau_{y y}$ value for the turbidity flow is over four times larger than for the equivalent saline flow on the $3^{\circ}$ slope. The difference between peak $\tau_{y y}$ values on the $9^{\circ}$ slope is less than on the $3^{\circ}$ slope although the turbidity flow still has a greater magnitude peak than the saline flow. Likewise on the $3^{\circ}$ slope, a prominent Reynolds shear stress $\left(\tau_{y x}\right)$ minimum occurs in the turbidity case only, with a near flat profile in the saline case and mean of about zero. On the $9^{\circ}$ slope $\tau_{y x}$ profiles are similar in shape having almost identical magnitude negative peaks just above $y^{\prime}=1$.

[25] The $T_{k e}$ profiles follow the shape of the dominant contributor to equation (3), in this case $u^{\prime 2}$. On the $3^{\circ}$ slope there is an increase in the difference between $T_{k e}$ profiles compared to the difference between $\tau_{x x}$ profiles (Figure 8c). This extra difference represents the additional contribution from $\tau_{y y}$ that is particularly significant in the turbidity flow case. On the $9^{\circ}$ slope $T_{k e}$ profiles for both flows have similar shapes and almost identical magnitudes up to $y^{\prime}=1$. The larger contribution from the $\tau_{y y}$ term in the turbidity case is matched by a larger contribution from the $\tau_{x x}$ term in the saline case.

\subsection{Variation in Turbulence Structure With Slope and Location}

[26] Steep slopes increase the energy available to the flow as, given the same initial density and discharge, the downslope buoyancy component is greater than on gentle slopes. At the break in slope, a sudden decrease in the downslope buoyancy component has little effect on shear-turbulence generation in saline flows, with $V$ and $\tau_{y x}$ having similar shapes (Figure 9a). A strong dependence of $\tau_{x x}$ and $\tau_{y y}$ on slope reflects increased energy made available, shown by $U_{d}$ and $U_{\max }$ positively correlating with slope (Table 3 ). For the turbidity flows, $V$ profiles are flatter than at Location A 


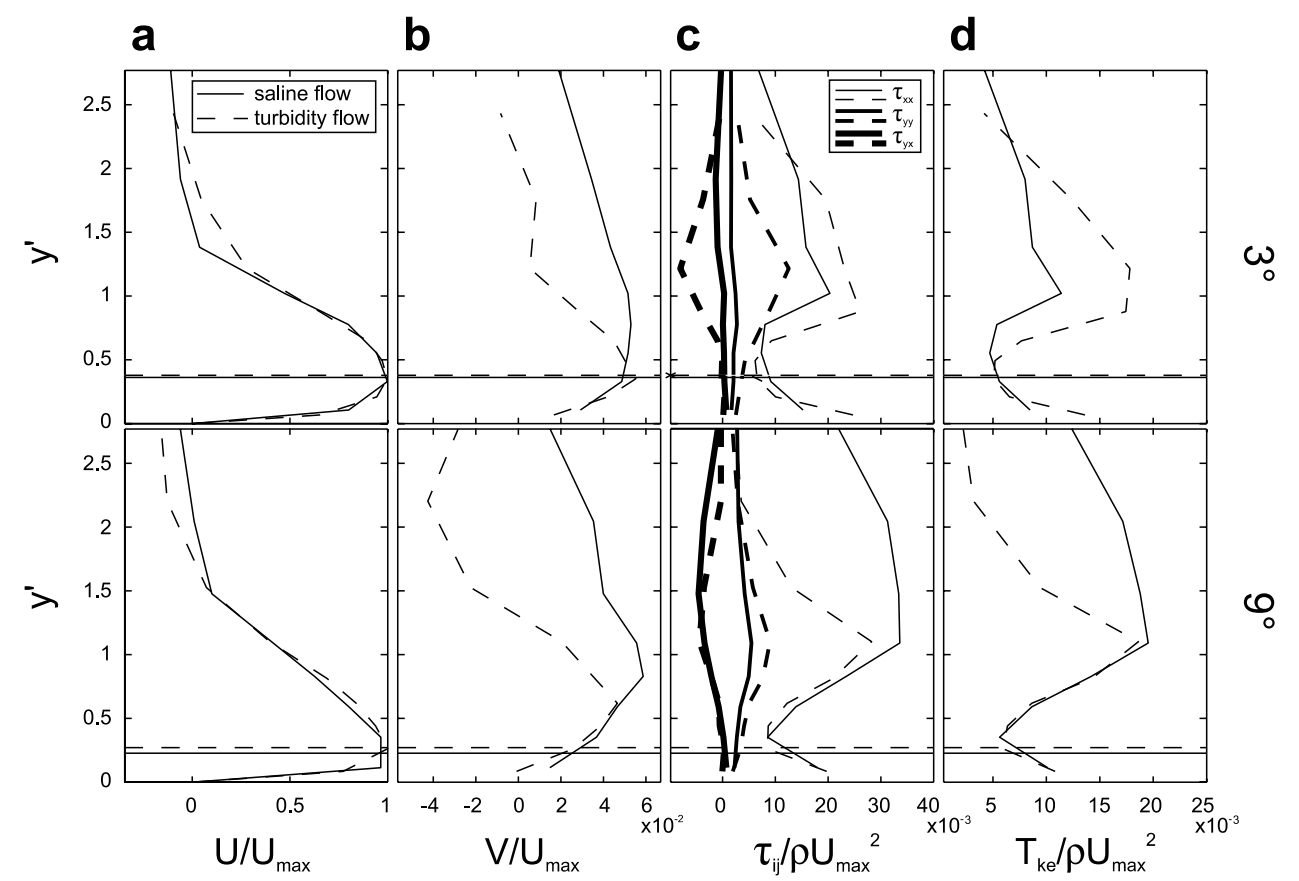

Figure 8. (a) Comparison of normalized $U$ profiles for both flow types taken from the $3^{\circ}$ and $9^{\circ}$ runs at Location A. (b) Normalized $V$ profiles showing the steep gradient of the turbidity flow profiles compared with the saline flows. (c) Normalized Reynolds stress components (see key for details). Note that the Reynolds normal stresses are plotted as $-\tau_{x x}$ and $-\tau_{y y}$ to make the graph clearer. (d) Profiles of normalized $T_{k e}$. The horizontal lines on all graphs are drawn at the heights of $U_{\max }$ for each flow.

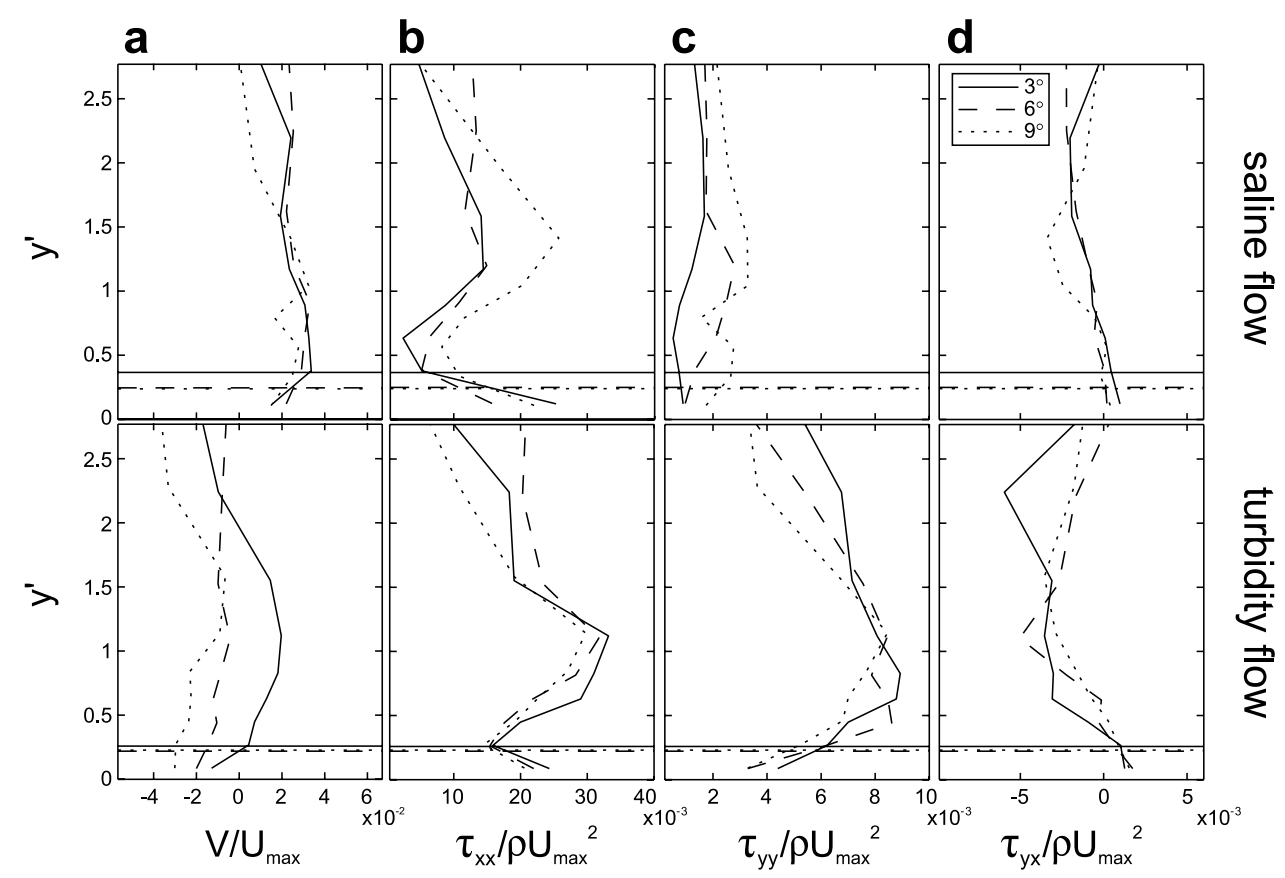

Figure 9. (a) Normalized $V$ profiles for the $3^{\circ}, 6^{\circ}$, and $9^{\circ}$ saline and turbidity flows at Location B. Turbidity flow profiles have a negative shift in magnitude compared with Location A (compare Figure 8) that increases with slope. (b) Normalized $-\tau_{x x}$ profiles. Peaks in saline flow profiles increase in magnitude with slope. (c) Normalized $-\tau_{y y}$ profiles that have little dependence on proximal slope in the turbidity cases. (d) Normalized $\tau_{y x}$ profiles that have little dependence on proximal slope in the turbidity cases. The horizontal lines on all graphs are drawn at the heights of $U_{\max }$ for each flow. 


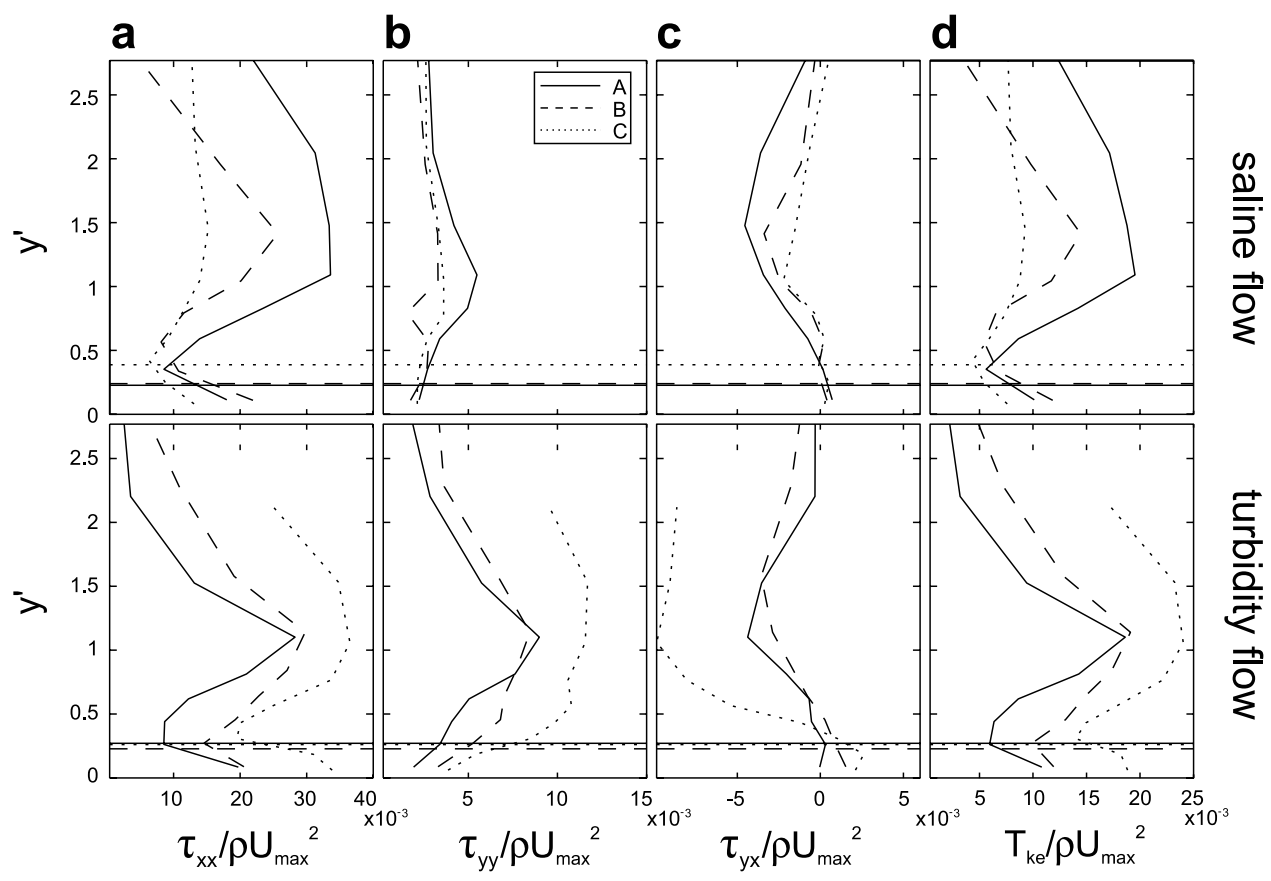

Figure 10. (a) Normalized $-\tau_{x x}$ profiles for the $9^{\circ}$ flows at all measurement locations. (b) Normalized $-\tau_{y y}$ profiles for the $9^{\circ}$ flows at all measurement locations. Saline flow magnitudes decrease downstream, whereas turbidity flow magnitudes increase downstream. (c) Normalized $\tau_{y x}$ profiles for the $9^{\circ}$ flows, reflecting a reduction in shear of the mean streamwise velocity profile downstream in the saline cases, and an increase in shear downstream in turbidity cases. Also note the flattening of the turbidity flow profile at Location B compared to Locations A and C. (d) Normalized $T_{k e}$ profiles for the same flows. The horizontal lines on all graphs are drawn at the heights of $U_{\max }$ for each flow.

and become more negative with increasing slope (compare Figures $8 b$ and 9a). There are small systematic differences in the magnitude of $\tau_{x x}$ and $\tau_{y y}$ profiles in flows issuing from different slopes, suggesting some continuing dependence of flow energy on slope.

[27] Figure 10 shows normalized Reynolds stress and turbulent kinetic energy profiles for the $9^{\circ}$ flows at all locations. For the saline flows, a reduction in shear of the mean streamwise velocity profile dominates the downstream decrease of $\tau_{x x}, \tau_{y x}$ and $T_{k e}$ magnitudes. $\tau_{y y}$ profiles have little dependence on location (Figure 10b). For turbidity flows normalized $T_{k e}$ increases downstream, arising from downstream increases of both $\tau_{x x}$ and $\tau_{y y}$ magnitudes. Only at Location $\mathrm{C}$ does $\tau_{y x}$ become increasingly negative (Figure 10c). Further, $\tau_{x x}$ and $T_{k e}$ profiles become flatter at the break in slope and although there is little change in peak magnitude from Locations A to B, there is an increase in the magnitude of the rest of the profiles, particularly when $0.2<y^{\prime}<1$ and $y^{\prime}>1$.

\subsection{Discussion}

\subsubsection{Effects of Slope Angle and Density Contrast on Flow Mechanics}

[28] Gray et al. [2005] showed that shear of the mean streamwise-velocity profile dominates turbulence production in turbidity flows and that $T_{k e}$ produced through the action of Reynolds normal stresses (from mean streamwise slowing) is transferred into mean bed-normal motion. Generally in wall jet flows, a change in sign of $\tau_{y x}$ around the level of $U_{\max }$ reflects shear-turbulence generated in the logarithmic and Gaussian parts of the flow, separated by
$U_{\max }$ [cf. Launder and Rodi, 1983; Buckee et al., 2001]. On the slope, peaks in $\tau_{x x}$ are associated with the largest gradients of the Gaussian $U$ profile and a much enhanced $\tau_{y y}$ peak in the upper Gaussian part of the turbidity flows is associated with strong $V$ gradients, suggesting that shear associated with the gradient may cause the effect (Figure 8).

[29] On gentle slopes a larger $T_{k e}$ peak occurs for turbidity flows, which although dominated by contributions from $\tau_{x x}$, have an extra contribution from $\tau_{y y}$ and a larger peak in $\tau_{y x}$. On steep slopes, saline flows have a similar magnitude (or slightly larger) $T_{k e}$ peak to turbidity flows since the greater downslope buoyancy component promotes faster $U$ velocities which increase shear of the $U$ profile (shown by increases in $\tau_{x x}$; Figure 8c). Thus, for the same range of slope angles $\left(0^{\circ}\right.$ to $\left.9^{\circ}\right)$, saline flows exhibit a more pronounced change in $U$ and $\tau_{x x}$ than turbidity flows. On steep slopes the greater downslope buoyancy component has a lesser effect on turbidity flows than on saline flows. This is thought to be because rapid deposition acts to slow the turbidity flows by reducing overall flow buoyancy, thus damping any increase in flow energy due to increases in $U$. However, turbidity flows on steep slopes are faster than turbidity flows on gentle slopes as steeper slopes promote increased sediment suspension (and thus maintenance of buoyancy). The separation of the influence of slope on $\tau_{x x}$ and that of the presence of sediment on $\tau_{y y}$ suggests that significantly different dynamics operate in saline and turbidity flows.

\subsubsection{Flow Adjustment at the Slope Break}

[30] At the slope break, normalized $T_{k e}$ for saline flows is reduced as mean streamwise velocities decay and shear 
turbulence production is reduced (Table 3 and Figures 9 and 10). In turbidity flows crossing slope breaks, an imbalance can arise between turbulence production from mean streamwise slowing and turbulence dissipation due to mean upward bed-normal motion [Gray et al., 2005]. In the present cases at Location B, mean downward fluidparticle motion is dependent on the preceding proximal slope angle. The $V$ profiles systematically become negative and flatten (Figure 9a) and peak $\tau_{y x}$ and $\tau_{y y}$ decrease (Figure 10b). Downward motion of particles occurs at the slope break owing to their inertia as part of the inherited downslope velocity component is now directed toward the bed. However, $\tau_{y y}$ increases in magnitude above and below the peak value at $c . y^{\prime}=1$ compared with Location A, suggesting that particle motion increases Reynolds normal stress components independently of mean velocity gradients. Thus turbulent accelerations are enhanced in the streamwise and bed-normal directions despite flattening of the $V$ gradient. As a consequence turbulence is produced over the entire flow thickness, Reynolds stress and $T_{k e}$ profiles become flatter and more sediment is maintained in suspension across the break in slope causing a reduction in deposit mass just downstream of the slope break (Figures 4 and 10).

\subsubsection{Flow on the Horizontal Floor}

[31] A downstream increase in normalized $T_{k e}$ for turbidity flows contrasts with the downstream decrease observed for saline flows. At Location $\mathrm{C}$, velocities of saline and turbidity flows issuing from all slopes converge and saline flows decelerate more rapidly than turbidity flows (Figure 6). In saline flows the majority of turbulence production comes from shear at the lower and upper flow boundaries through the gradient of mean streamwise velocity. Transfer of energy through the action of Reynolds normal stresses is balanced as turbulence production from mean streamwise slowing is dissipated by bed-normal flow expansion. In turbidity flows, turbulent energy produced from mean streamwise deceleration is available to suspend sediment. At Location $\mathrm{C}$, because of the much reduced particle size and concentration, it is likely that suspension is able to occur more readily [cf. Leeder et al., 2005]. A steep gradient in the $V$ profile develops, peak $\tau_{y y}$ values increase and greater sediment transport across the break in slope promotes further enhancement of Reynolds normal stresses (Figures 5b and 10b). Thus shear production of turbulence is enhanced by the steep $V$ gradient and also by the presence of the particles that act independently on normal stress components, unlike in saline flows where normal stresses simply reflect the contributing components to the overall shear stress, $\tau_{y x}$.

[32] A result of the enhancement of Reynolds stresses in turbidity flows is that on initial zero gradients, turbidity flows maintain faster mean streamwise velocities than saline flows, as $T_{k e}$ is maintained in the absence of any downslope buoyancy component despite the loss of overall flow buoyancy through deposition. At the most distal locations, increased $T_{k e}$ (relative to mean streamwise velocity and density) is able to suspend the lower concentration and finer size sediment and the rate of mean velocity decay is reduced compared with saline flows. At these locations a state of partial autosuspension may occur in the Gaussian layer [Leeder et al., 2005].
Table 5. The $u^{\prime}: v^{\prime}$ Ratios Calculated Using Maximum and LayerAveraged Values for Each Component for Both Flow Types

\begin{tabular}{lcc}
\hline & Saline & Turbidity \\
\hline$u_{\text {max }}^{\prime}: v_{\text {max }}^{\prime}$ & 5.1 & 3.4 \\
$u_{\text {layer }}^{\prime}: v_{\text {layer }}^{\prime}$ & 4.5 & 2.7 \\
\hline
\end{tabular}

\subsubsection{Effects of Sediment Particles on Stratification and Turbulence}

[33] Differences in $R i_{g}$ between saline and turbidity flows arise mainly because of the additional effect of sedimentation upon $\frac{\partial \rho}{\partial y}$ (Figure 7a). In general, higher local densities and greater density gradients are expected in turbidity flows owing to a downward increase in particle concentration during settling and sedimentation. In saline flows density cannot increase above the initial value, $1014 \mathrm{~kg} \mathrm{~m}^{-3}$. Entrainment of ambient water can reduce the density, but in these experiments $R i_{g}$ is usually unfavorable for mixing (Figure $7 \mathrm{~b}$ ). In turbidity flows density can vary considerably. It can locally increase above the original value by settling and may be reduced by deposition and entrainment of ambient water $\left(R i_{g}\right.$ $<0.25$ over much of the flows; Figure $7 b$ ).

[34] An increase in turbulence in the presence of suspended grains has been documented in studies of suspended sediment transport in recirculating open-channel experimental flows [Best et al., 1997; Bennett et al., 1998]. The addition of suspended sediment to clear water flows causes a reduction in the von Kármán constant $(\kappa)$ by some $20 \%$ and a reduction in the mixing length $(l)$ in the logarithmic layer [Best et al., 1997; Bennett et al., 1998]. This is accompanied by major increases in the vertical fluid turbulent intensity, with sediment-transporting flows having $\sim 25 \%$ greater $v^{\prime}$. In these channelized flows the relative motion of particles and fluid, the effects of added inertial mass of near-bed grains on fluid and modification of coherent wall eddies in the turbulent equilibrium layer have been suggested to cause the increase in $v^{\prime}$ [Best et al., 1997; Bennett et al., 1998]. Despite hydraulically smooth boundaries, absence of bedforms and very low particle Reynolds numbers, our turbidity flows also have marked enhancement of two-dimensional Reynolds stresses and turbulent kinetic energy compared with the saline flows (Figures 9 and 11), suggesting that another more general mechanism might be at work.

[35] The wall jet flows described here show Reynolds stress enhancement of c. $40 \%$ compared with the $25 \%$ observed in free-surface channel flows (Table 5). This enhancement occurs in the Gaussian layer (though some effect is seen in the upper log-layer; Figures $8 \mathrm{c}$ and $8 \mathrm{~d}$ ) peaking at or just above $y^{\prime}=1$. This suggests that the reasons for the enhancement are kinematically unrelated to wall processes such as coherent wall-layer eddy formation and development. Instead they must be due to particleinduced modification of turbulence generation processes associated with the wall-jet upper free-shear layer. This may be due to the inertial effect of the suspended particles (discussed below) that results in an increase in shear-driven mixing processes.

[36] Although our experiments involve comparison of dynamically similar, negatively buoyant wall jets, major contrasts in flow behavior between the saline and turbidity flows may be predicted from consideration of the necessary 
conditions for the Boussinesq approximation in density flows. The Boussinesq form of the Navier-Stokes equations [see, e.g., Tritton, 1988, equation (14.7)] is expressed here for a nonturbulent flow of density $\left(\Delta \rho+\rho_{0}\right)$,

$$
\begin{aligned}
\left(\rho_{0}\right) \frac{\mathrm{D} u}{\mathrm{D} t} & \equiv\left(\rho_{0}\right) \frac{\partial u}{\partial t}+\left(\rho_{0}\right) u \cdot \nabla u=\sum F \\
& \equiv-\nabla P+\mu \nabla^{2} u+\left(\Delta \rho+\rho_{0}\right) g
\end{aligned}
$$

[37] The Boussinesq approximation thus assumes that any increase of density, $\Delta \rho$, has negligible effect upon (turbulent) fluid accelerations. In our saline flows, the Boussinesq condition may well be satisfied, but for turbidity flows, with a volumetrically significant distribution of tiny, solid pointmasses of excess density, there exist major enhancement of inertial reaction to the extra applied forces. Ignoring the effects of particles on viscous forces in turbulent flows and the irrelevance of the exact cause of excess density to the reduced gravity term, the extra force component needed to cause the observed accelerations may arise from enhancement of the pressure gradient term, $-\nabla P$ in the NavierStokes equations. It is suggested that this is due to the presence of particles, for we know from the classic experiments of Bagnold [1954] that pressures and pressure gradients increase even when neutrally buoyant solids are added to shear flows. Inertial reaction to the extra pressure-driving force manifests itself in the observed enhanced two-dimensional turbulent accelerations, or as conventionally envisaged, increased Reynolds "stress" per unit volume, $-\rho u_{i} u_{j}$.

\subsection{Implications for Environmental Flows and Deposits}

[38] Gravity currents frequently flow across a range of topographies in the natural environment. The end-member analogues of a saline (or nonparticulate) flow and a depositional turbidity flow presented in this study are applicable to a broad range of geophysical flows and also to a lesser extent in the study of turbulent wall jets in engineering applications. They are particularly relevant to natural turbidity flows occurring in lakes and oceans. Sediment size plays a critical role in controlling both general flow behavior and the detailed turbulence structure of these flows [Gladstone et al., 1998; Salaheldin et al., 2000]. The importance of grain size in natural turbidite systems is illustrated by the variability of bed types and structures encountered in them [Normark et al., 1993]. Our experiments suggest that some of this variety may be explained by different turbulent processes occurring in the flows that depend on the presence, type and density of particles in the flow. For example, clay-dominated turbidity flows may behave more like saline flows, whereas sandy flows may behave like the turbidity flows described here.

[39] The experiments described in this paper show that under subcritical conditions, turbidity flows transfer energy away from the levels of $U_{\max }$ to suspend sediment. On very gentle or horizontal gradients, momentum transfer processes (and turbulence production) are more vigorous than in saline flows because the flow has adjusted its $V$ profile to carry sediment and Reynolds normal stresses are enhanced due to the presence of particles. These in turn giving the flow mean streamwise motion. In an equivalent saline flow, $U_{\max }$ depends solely on the driving buoyancy force, and hence slope angle. Thus turbidity flows are able to travel faster than saline flows on horizontal gradients and this may partly explain why some deep ocean turbidite sands are located many hundreds of kilometers from their source.

[40] Loss of capacity has been proposed as the fundamental process controlling deposition from turbidity flows [Hiscott, 1994]. Data from turbidity flows indicate that the ability of the flow to maintain its load increases downstream as sediment is deposited (i.e., reducing flow capacity) and a state of partial autosuspension may be achieved in the Gaussian part of the flow under subcritical conditions [Leeder et al., 2005]. It is therefore expected that the competence of subcritical turbidity flows on gentle gradients may be greater than that indicated by saline flows, as faster mean velocities and partial autosuspension will act to maintain any suspended load. Loss of capacity from the logarithmic layer may indeed govern deposition, but the role of competence must become important as states of autosuspension are reached. Continued deposition from the logarithmic layer will eventually lead to dissipation, although it is possible that very fine sediment will be able to drive the flow at very low velocities (akin to saline flows on gentle gradients). For turbidity flows not to lose any capacity as they travel, autosuspension must be achieved in the logarithmic layer through wall-shear turbulence generation, and this is only likely at very high velocities and under supercritical conditions (i.e., on steep slopes) concurring with Pantin [2001]. Further investigation is required to compare supercritical saline and turbidity flows, although data from a supercritical saline flow indicate that a different turbulent structure may occur [Buckee et al., 2001]

[41] Further implications of this work are in the modeling of turbidite bed geometries in the hydrocarbon industry. Flows driven by dissolved substances will respond and propagate differently than those driven by particulate matter. In the mathematical modeling of such flows, explicit account of the particle-fluid effects and different mixing properties discussed in this study may assist in the more accurate determination of flow kinematics and deposit geometries. Further, the change in turbulent properties downstream across a gradient change, in particular the relative increase in $T_{k e}$ downstream in turbidity flows and increased maintenance of sediment in suspension across a slope break may help to explain the occurrence of coarser grained sandy deposits on relatively gentle basin slopes in turbidite channels [Normark et al., 1993].

[42] Finally we stress that these experimental results apply strictly to 2-dimensional flows that are constrained in the lateral direction. Significantly different effects may occur in flows free to expand at the base of slope, or in channelized flows that only partially occupy the channel. Further experimental work is necessary to understand the influence of grain size and composition and flow uniformity in density currents, in particular when currents are free to erode sediment from the bed [e.g., Parker et al., 1986].

\section{Conclusions}

[43] Three main effects influence experimental flow evolution: sediment transport and sedimentation, proximal 
slope angle and the presence of a slope break. The influence these have and the way they interact differ depending on flow type. Flow morphology is similar, although head shape does change with slope angle. Turbidity flows mix more vigorously than equivalent saline flows. Mean streamwise velocity structure of both flow types is similar although significant gradients and peaks occur in profiles of mean bed-normal velocity for turbidity flows. The presence of sediment causes an inertial reaction of the fluid recognized by peaks in Reynolds stresses occurring in the Gaussian flow layer. Failure of the Boussinesq approximation arises because the excess density of point masses of suspended sediment causes enhanced fluid accelerations owing to an increase in the pressure gradient term of the Navier-Stokes equations. The increased acceleration would account for the observed distribution of Reynolds stresses with height and increased mixing in turbidity flows.

[44] Momentum transfer through the action of turbulent velocity fluctuations differs in saline and turbidity flows, because particles independently affect momentum transfer processes through the action of Reynolds normal stresses compared with momentum transfer resulting from gradients of mean velocity. Transfer of energy from streamwise deceleration into mean upward motion is inhibited as turbulent accelerations are preferentially enhanced in the streamwise and bed-normal directions. This accounts for the increased maintenance of sediment in suspension across the break in slope, faster propagation of turbidity flows than saline flows on gentle gradients and an increase in normalized turbulent kinetic energy downstream in turbidity flows. Saline flows decrease turbulent kinetic energy relative to mean flow velocity downstream, as the downslope component of the driving force tends to zero and maximum mean streamwise velocities reduce and velocity gradients flatten, reducing shear production of turbulence. Turbidity flows may reach a state of partial autosuspension in the Gaussian layer at distal locations, as maximum mean streamwise velocities are maintained and a lower concentration and finer sediment load is suspended.

\section{Notation}

$\begin{aligned} d_{\text {mass }} & \text { deposit mass. } \\ F & \text { body force term. } \\ F r & \text { Froude number. } \\ h & \text { flow thickness. } \\ g & \text { gravitational vector. } \\ g & \text { gravitational constant. } \\ g^{\prime} & \text { reduced gravity. } \\ P & \text { pressure. } \\ R e & \text { Reynolds number. } \\ R i_{g} & \text { gradient Richardson number. } \\ T_{k e} & \text { turbulent kinetic energy per unit volume. } \\ \boldsymbol{u} & \text { velocity vector. } \\ u & \text { streamwise velocity. } \\ u^{\prime} & \text { fluctuating component of streamwise velocity. } \\ u_{\text {max }}^{\prime} & \text { maximum streamwise fluctuating component. } \\ u_{\text {layer }}^{\prime} & \text { mean streamwise fluctuating component in layer. } \\ u_{i} & \text { instantaneous streamwise velocity. } \\ U & \text { time-averaged streamwise velocity at-a-point. } \\ U_{d} & \text { depth-averaged streamwise velocity. }\end{aligned}$

$U_{d \log }$ depth-averaged streamwise velocity in the logarithmic layer.

$U_{d \text { Gaus }}$ depth-averaged streamwise velocity in the Gaussian layer.

$U_{\max }$ maximum mean streamwise velocity.

$U_{\text {turb }}$ depth-averaged velocity for turbidity flow.

$U_{\text {sal }}$ depth-averaged velocity for saline flow.

$v$ bed-normal velocity.

$v^{\prime}$ fluctuating component of bed-normal velocity.

$v_{\max }^{\prime}$ maximum bed-normal fluctuating component.

$v_{\text {layer }}^{\prime}$ mean streamwise fluctuating component in layer.

$v_{i}$ instantaneous bed-normal velocity.

$V$ time-averaged bed-normal velocity.

$V_{\max }$ maximum mean bed-normal velocity.

$y$ height.

$y^{\prime}$ normalized height.

$\kappa$ von Kármán constant.

$\mu$ viscosity.

$v$ dynamic viscosity of fluid at $15^{\circ} \mathrm{C}$.

$\theta$ slope.

$\rho$ density.

$\rho_{0} \quad$ initial density.

$\rho_{a}$ density of ambient fluid.

$\rho_{c}$ density of flow.

$\Delta \rho$ change in density.

$\tau_{i j} \quad i$ th and $j$ th components of Reynolds stress.

$\tau_{x x}$ streamwise Reynolds normal stress.

$\tau_{y y}$ bed-normal Reynolds normal stress.

$\tau_{y x}$ Reynolds shear stress.

[45] Acknowledgments. Many thanks to Rick Bryant, Gareth Flowerdew, Brendan O'Brien, Stuart Rix, Alan Marsden, and Martin Russell for assistance with equipment construction and maintenance of the flume. We thank Jim Best for loan of the UDVP from the University of Leeds and Mark Franklin for technical support with the UDVP. Thanks also to Kathryn Amos, Jaco Baas, Heqing Huang, and the Journal of Geophysical Research Editor for constructive comments on this work. Thomas Gray was in receipt of NERC studentship NER/S/A/2001/06143 while undertaking this research and thanks Jim Best and Richard Hey for a stimulating viva discussion.

\section{References}

Altinakar, M. S., W. H. Graf, and E. J. Hopfinger (1996), Flow structure in turbidity currents, J. Hydraul. Eng., 34, 713-718.

Baas, J. H., W. D. McCaffrey, P. D. W. Haughton, and C. Choux (2005), Coupling between suspended sediment distribution and turbulence structure in a laboratory turbidity current, J. Geophys. Res., 110, C11015, doi:10.1029/2004JC002668.

Bagnold, R. A. (1954), Experiments on a gravity-free dispersion of large solid spheres in a Newtonian fluid under shear, Proc. R. Soc. London, Ser. A, 225(1160), 46-63.

Bennett, S. J., J. S. Bridge, and J. L. Best (1998), Fluid and sediment dynamics of upper stage plane beds, J. Geophys. Res., 103(C1), 12391274

Best, J. L., S. J. Bennett, J. S. Bridge, and M. R. Leeder (1997), The modulation of turbulence by sediment over plane beds at low transport rates, J. Hydraul. Eng., 123, 1118-1129.

Best, J. L., A. D. Kirkbride, and J. Peakall (2001), Mean flow and turbulence structure of sediment-laden gravity currents: New insights using ultrasonic Doppler velocity profiling, in Particulate Gravity Currents, edited by W. D. McCaffrey et al., pp. 159-172, Blackwell Sci., Malden, Mass.

Britter, R. E., and P. F. Linden (1980), The motion of the front of a gravity current travelling down an incline, J. Fluid Mech., 99, 531-543.

Buckee, C., B. C. Kneller, and J. Peakall (2001), Turbulence structure in steady, solute-driven gravity currents, in Particulate Gravity Currents, edited by W. D. McCaffrey et al., pp. 173-187, Blackwell Sci., Malden, Mass.

Daly, R. A. (1938), Origin of submarine canyons, Am. J. Sci., 31, 410420 . 
Ellison, T. H., and J. S. Turner (1959), Turbulent entrainment in stratified flows, J. Fluid Mech., 6, 423-448.

García, M. H. (1993), Hydraulic jumps in sediment driven bottom currents, J. Hydraul. Eng., 199, 1094-1117.

Gladstone, C., J. C. Phillips, and R. S. J. Sparks (1998), Experiments on bidisperse, constant-volume gravity currents: Propagation and sediment deposition, Sedimentology, 45, 833-843.

Gray, T. E., J. Alexander, and M. R. Leeder (2005), Quantifying velocity and turbulence structure in depositing sustained turbidity currents across breaks in slope, Sedimentology, 52, 467-488.

Härtel, C., F. Carlsson, and M. Thunblom (2000), Analysis and direct numerical simulation of the flow at a gravity-current head, 2, The lobeand-cleft instability, J. Fluid Mech., 418, 213-229.

Hiscott, R. N. (1994), Loss of capacity, not competence, as the fundamental process governing deposition from turbidity currents, J. Sediment. Res., 64(2), 209-214

Huppert, H. E., and J. E. Simpson (1980), The slumping of gravity currents, J. Fluid Mech., 99, 785-799.

Johnson, D. (1938), The origin of submarine canyons, J. Geomorphol., 1, $111-340$.

Keulegan, G. H. (1957), An experimental study of the motion of saline water from locks into fresh water channels, Rep. 5168, Natl. Inst. of Stand. and Technol., Gaithersburg, Md.

Kineke, G. C., K. J. Woolfe, S. A. Kuehl, J. D. Milliman, T. M. Dellapenna, and R. G. Purdon (2000), Sediment export from the Sepik River, Papua New Guinea: Evidence for a divergent sediment plume, Cont. Shelf Res., 20, 2239-2266.

Kneller, B. C., and C. Buckee (2000), The structure and fluid mechanics of turbidity currents: A review of some recent studies and their geological implications, Sedimentology, 47, suppl. 1, 62-94.

Kneller, B. C., S. J. Bennett, and W. D. McCaffrey (1999), Velocity structure, turbulence and fluid stresses in experimental gravity currents, J. Geophys. Res., 104(C3), 5381-5391.

Kuenen, P. H., and C. I. Migliorini (1950), Turbidity currents as a cause of graded bedding, J. Geol., 58, 91-127.

Launder, B. E., and W. Rodi (1983), The turbulent wall jet: Measurements and modeling, Annu. Rev. Fluid Mech., 15, 429-459.

Leeder, M. R., T. E. Gray, and J. Alexander (2005), A new dynamic criterion for maintenance of turbulent sediment suspensions in open channel and wall jet turbidity flows, Sedimentology, 52, 683-694.

Macías, J. L., J. M. Espíndola, M. Bursik, and M. F. Sheridan (1998), Development of lithic-breccias in the 1982 pyroclastic flow deposits of El Chichon Volcano, Mexico, J. Volcanol. Geotherm. Res., 83, 173-196.

McCaffrey, W. D., C. M. Choux, and J. H. Baas (2003), Spatio-temporal evolution of velocity structure, concentration and grain size stratification within experimental particulate gravity currents, Mar. Pet. Geol., 20, $851-860$

Middleton, G. V. (1966), Experiments on density and turbidity currents, I, Motion of the head, Can. J. Earth Sci., 3, 523-546.

Middleton, G. V. (1993), Sediment deposition from turbidity currents, Annu. Rev. Earth Planet. Sci., 21, 89-114.

Miles, J. W. (1961), On the stability of heterogeneous shear flows, J. Fluid Mech., 10, 496-508.

Mulder, T., and J. Alexander (2001), Abrupt change in slope causes variation in the deposit thickness of concentrated particle-driven density currents, Mar. Geol., 175, 221-235.
Mulder, T., J. P. M. Syvitski, and K. I. Skene (1998a), Modelling of erosion and deposition by turbidity currents generated at river mouths, J. Sediment. Res., 68, 124-137.

Mulder, T., B. Savoye, D. J. W. Piper, and J. P. M. Syvitski (1998b), The Var submarine sedimentary system: Understanding Holocene sediment delivery processes and their importance to the geological record, in Geological Processes on Continental Margins: Sedimentation, Mass-Wasting and Stability, vol. 129, edited by M. S. Stoker et al., Geol. Soc. Spec. Publ., 145-166.

Mulder, T., J. P. M. Syvitski, S. Migeon, J.-C. Faugeres, and B. Savoye (2003), Marine hyperpycnal flows: Initiation, behaviour and related deposits, A review, Mar. Petrol. Geol., 20, 861-882.

Normark, W. R., H. Posamentier, and E. Mutti (1993), Turbidite systems: State of the art and future directions, Rev. Geophys., 31, 91-116.

Pantin, H. M. (2001), Experimental evidence for autosuspension, in Particulate Gravity Currents, edited by W. D. McCaffrey et al., pp. 189-205, Blackwell Sci., Malden, Mass.

Parker, G., Y. Fukushima, and H. M. Pantin (1986), Self-accelerating turbidity currents, J. Fluid Mech., 171, 145-181.

Parker, G., M. H. García, Y. Fukushima, and W. Yu (1987), Experiments on turbidity currents over an erodible bed, J. Hydraul. Res., 25(1), $123-147$.

Parsons, J. D., J. M. Bush, and J. P. M. Syvitski (2001), Hyperpycnal plume formation from riverine outflows with small sediment concentrations, Sedimentology, 48, 465-478.

Peakall, J., M. Felix, B. McCaffrey, and B. C. Kneller (2001), Particulate gravity currents: Perspectives, in Particulate Gravity Currents, edited by W. D. McCaffrey et al., pp. 1-8, Blackwell Sci., Malden, Mass.

Pratson, L. E., J. Imran, J. P. M. Parker, J. P. M. Syvitski, and E. Hutton (2000), Debris flows vs. turbidity currents: A modeling comparison of their dynamics and deposits, in Fine-Grained Turbidite Systems, edited by A. H. Bouma and C. G. Stone, AAPG Mem., 72, 57-71.

Salaheldin, T. M., J. Imran, M. H. Chaudry, and C. Reed (2000), Role of fine-grained sediment in turbidity current flow dynamics and resulting deposits, Mar. Geol., 171, 21-38.

Siegenthaler, C., and J. Buhler (1985), The kinematics of turbulent suspension currents (turbidity currents) on inclined boundaries, Mar. Geol., 64, $19-40$.

Simpson, J. E., and R. E. Britter (1979), The dynamics of the head of a gravity current advancing over a horizontal surface, J. Fluid Mech., 94 477-495.

Stacey, M. W., and A. J. Bowen (1988), The vertical structure of density and turbidity currents: Theory and observations, J. Geophys. Res. 93(C4), 3528-3542.

Strang, E. J., and J. S. Fernando (2001), Entrainment and mixing in stratified shear flows, J. Fluid Mech., 428, 349-386.

Tritton, D. J. (1988), Physical Fluid Dynamics, Oxford Univ. Press, New York.

Woods, A. W., M. Bursik, and A. V. Kurbatov (1998), The interaction of ash flows with ridges, Bull. Volcanol., 60, 38-51.

J. Alexander, T. E. Gray, and M. R. Leeder, School of Environmental Sciences, University of East Anglia, Earlham Road, Norwich, Norfolk NR4 7TJ, UK. (j.alexander@uea.ac.uk) 